\title{
Fire Growth Rates in Underground Facilities
}

\author{
S. BENGTSON \\ Brandskyddslaget, Rönnvägen 5, S-121 34 Enskededalen, Sweden \\ G. RAMACHANDRAN \\ Visiting Professor, Glasgow Caledonian University and University of Hertfordshire, United Kingdom
}

\begin{abstract}
Assuming an exponential model, fire growth rates are estimated in this paper for four types of occupancies - railway properties, public car parks, road tunnels and power stations. The results are based on data for area damaged and duration of burning in actual fires contained in fire statistics. It is shown clearly that the maximum value (upper confidence limit) of growth rates in individual fires is distinct from the maximum value of the average growth rate in all fires. The former maximum is considerably higher than the latter and represents more realistically the worst case scenario.
\end{abstract}

The statistically-determined fire growth rate discussed in this paper does not relate to any particular object. It is a combined (average) estimate for several objects involved in a fire and takes into account the stochastic (random) nature of fire spread from object to object. Such an estimate allowing for uncertainties governing the development of a real fire can not be provided, at present, by any deterministic model based on heat output data from experiments.

KEYWORDS: exponential model, actual fires, average growth rate, individual growth rate, worst case scenario.

\section{INTRODUCTION}

For determining the fire protection requirements of a building, an average fire growth rate is required which is based on all combustible materials in the building rather than a single material or a selected group of materials. This parameter can not be estimated, at present, by any deterministic (zone or field) model involving physical quantities such as heat output or release rates. Experimental data for validating such models are available only for a limited number of materials or objects. Deterministic models do not provide estimates of probabilities (uncertainties) associated with growth rates.

For the reasons mentioned above, it would be useful to estimate fire growth rates from data on area damaged and duration of burning in real fires rather than experimental fires. Such data are available for some years for fires attended by fire brigades in the United Kingdom. Based on these data, average fire growth rates can be estimated for different types of occupancies together with their standard deviations 
quantifying the uncertainties surrounding the estimated values. The maximum growth rate corresponding to any specified probability level would represent the "worst case" scenario.

In this paper, data on real fires are statistically analysed for estimating fire growth rates for four types of occupancies - railway properties, public car parks, road tunnels and power stations. The results are based on data for the three years 1985-87 for the first two types of buildings and for the five years 1979 and 1984-87 for the other two types. These statistics relating to fires attended by the fire brigades were provided by the Fire Statistics Section of the Home Office, United Kingdom.

\section{FIRE GROWTH}

\subsection{Exponential Model}

Area damaged in a fire is approximately proportional to heat output or release. Hence, following scientific theories [1,2] and experimental results [3] we can postulate

$A(t)=A(0) \exp (\beta t)$

where

$A(t)=$ area damaged (sq. metres) in $t$ minutes after the start of the fire.

$\mathrm{A}(0)=$ area (sq. metres) initially ignited

$\beta \quad=$ fire growth parameter.

The exponential model in equation (1) provides a reasonably good description of fire growth except, perhaps, for the very early stage of fire growth when fire size can increase according to a square or some other power of $t[2,4]$. According to Butcher [5] there is practically no difference between parabolic [4] and exponential fire growth curves. The exponential model has been fruitfully applied in some previous studies concerned with the economic value of early detection of fires and fire brigade performance $[6,7,8]$.

It should be noted that, as specified in equation (1), $A(t)$ is not the area damaged (size) during the $t^{\text {th }}$ minute. It is the total area damaged in $t$ minutes and includes both the area burning at time $t$ and the area already burnt. In this sense, $A(t)$ is the cumulative area affected during the period up to $t$ minutes since the start of the fire. The derivative of $A(t)$ is $\beta \cdot A(t)$ which denotes the rate of increase of damaged area.

The parameters (constants) $\beta$ and $A(0)$ can be estimated by using the data on $A(t)$ and $t$ for a (large) sample of fires in a least square regression analysis based on the following model: 
Equation (2) follows from equation (1). The "doubling time" given by

$d_{b}=\log _{e} 2 / \beta=(0.6391) / \beta$

is the time for area damaged to double in size and is a constant for the exponential model.

\subsection{Upper Confidence Limit for Average Growth Rate}

The constant $\beta$ measuring the rate of fire growth is an average value over the duration of burning and different materials ignited during fire development.

The standard deviation of $\beta, \sigma_{3}$, is given by the square root of

$\sigma_{\beta}^{2}=\frac{\sigma^{2}}{\sum_{n} T-\mu_{t}^{2}}$

where $\mu_{1}$ is the mean value of duration of burning, $T$, for the $n$ fires in the sample analysed. The parameter $\sigma$ is the standard deviation of the "residual error" estimated in the regression analysis. This error is the difference between the logarithms of the observed value of damage in a fire and the corresponding value for that fire with duration of burning $t$ predicted by equation (2). The coefficient of variation $\left(\sigma_{\beta} / \beta\right)$ measures the precision with which $\beta$ has been estimated. As a general rule, if the value for this coefficient is less than 0.15 , the estimated value of $\beta$ may be regarded as reliable as observed in six out of seven cases investigated in this paper - see Table 1.

If $\beta$ is assumed to have a normal distribution, its upper confidence limit denoting the "worst case" scenario is given by

$\mathrm{U}_{\beta}=\beta+1.96 \sigma_{\beta}$

The probability of average growth rate in a fire exceeding the upper limit (maximum) is 0.025 . The corresponding lower confidence limit (minimum) of the doubling time, denoted by $\mathrm{L}_{\mathrm{db}}$ is:

$\mathrm{L}_{\mathrm{db}}=(0.6391) / \mathrm{U}_{\mathrm{b}}$

The probability of (average) doubling time falling short of its lower limit $\mathbf{L}_{\mathrm{db}}$ is 0.025 .

\subsection{Upper Confidence Limit for Individual Growth Rate}

It is common practice in most regression problems to evaluate the fluctuations in the neighbourhood of the "slope" parameter $\beta$ which in our study is the growth rate 
averaged over all the fires in the sample analysed - see, for example, Ramachandran [8]. The fluctuations are random and are hence expressed in terms of confidence limits. It should be emphasized that $\mathrm{U}_{\beta}$ is the upper limit of the average growth rate and not of individual growth rates which have wider fluctuations around their expected value $\beta$. The difference between these two parameters of the growth rate is explained as follows.

Every fire individually provides an estimate of the growth rate as given by the ratio

$$
\Theta=Y / t
$$

where

$$
\begin{aligned}
& Y=y-\log A(0) \\
& y=\log A(t)
\end{aligned}
$$

As in a least square regression analysis based on equation (2), $\Theta$ is a constant independent of the duration of burning, $t$. Hence, according to statistical theory [9], the expected value of $\Theta$ is given by

$$
(\overline{\mathrm{Y}} / \overline{\mathrm{t}})=[\overline{\mathrm{y}}-\log \mathrm{A}(0)] / \overline{\mathrm{t}}
$$

where $\bar{Y}$ is the mean of $Y$ in equation (8), $\bar{y}$ mean of $y$ in equation (9) and $\bar{t}$ the mean of $t$. It may be seen that the right hand side of equation (10) is equal to $\beta$ since

$\bar{y}=\log A(0)+\beta \bar{t}$

is one of the two "normal equations" in a least square regression analysis based on equation (2).

Also, according to statistical theory [9], the standard deviation of $\Theta$ is the square root of

$$
\sigma_{\Theta}^{2}=\frac{\sigma_{Y}^{2} \times \bar{T}^{2}-\sigma_{T}^{2} \times \bar{Y}^{2}}{\bar{T}^{2}\left[\sigma_{T}^{2}+\bar{T}^{2}\right]}
$$

where $\sigma_{\mathrm{Y}}^{2}$ is the variance of $\mathrm{Y}$ and $\sigma_{\mathrm{T}}^{2}$ the variance of $\mathrm{t}$. The variances of $\mathrm{Y}$ and $\mathrm{y}$ are equal; hence $\sigma_{\mathrm{Y}}^{2}=\sigma_{\mathrm{y}}^{2}$

It can be shown that equation (12) reduces to:

$$
\sigma_{\Theta}^{2}=\frac{\sigma_{\mathrm{y}}^{2}\left(1-\rho^{2}\right)}{\sigma_{\mathrm{T}}^{2}+\overrightarrow{\mathrm{T}}^{2}}=\frac{\sigma^{2}}{\sigma_{\mathrm{T}}^{2}+\overline{\mathrm{T}}^{2}}
$$


where $\rho$ is the coefficient of correlations between $Y$ and $t$ and $\sigma^{2}$ is the residual variance defined in equation (4).

In problems concerned with fire safety, the "worst case" scenario is represented by the maximum value of the growth rate $\Theta$ for an individual fire rather than the maximum value of the average rate $b$. Although the expected value of $\Theta$ is $\beta$, the standard deviation of $\Theta, \sigma_{\Theta}$, given by equation (13) is greater than that of $\beta, \sigma_{\beta}$, given in equation (4). The upper confidence limit for $\Theta$ is given by

$\mathrm{U}_{\Theta}=\beta+1.96 \sigma_{\Theta}$

The probability of growth rate in a fire exceeding the maximum $U_{\odot}$ is 0.025 . The corresponding doubling time of $\Theta$ can be derived from an equation similar to (1).

\section{DATA}

Fire statistics compiled by the Home Office, United Kingdom provide an estimate of the total duration of burning, $t$, for each fire as the sum of the following four periods:

$t_{1} \quad$ - ignition to detection or discovery of fire

$t_{2} \quad$ - detection to calling fire brigade

$t_{3}$ - call to arrival of brigade at the scene of fire (attendance time)

$\mathrm{t}_{4} \quad$ - arrival to the time when fire is brought under control by brigade (controltime).

$t_{4}$ denotes the duration up to time when the fire has been effectively controlled or surrounded by the brigade and a message is sent to the fire station to stop the despatch of further reinforcements. There is a fifth period, $t_{s}$, from control to extinguishment for which information is not available. However, the growth of fire during this period is practically negligible such that it need not be included in any statistical investigation. In this report, the sum of the four periods, $t_{1}$ to $t_{4}$ has been considered as an estimate of $t$ for calculating the fire growth rate and doubling time.

Fire brigades in the United Kingdom are required to estimate, for each fire, the discovery time $t_{1}$ according to the following classification:

(i) discovered at ignition $\left(t_{1}=0\right)$

(i i) discovered under 5 minutes after ignition

(iii) discovered between 5 and 30 minutes after ignition

(iv) discovered more than 30 minutes after ignition. 
For adding $t_{1}$ to the other three time periods, average values of 2,17 and 45 minutes had to be assumed for the three categories (ii), (iii) and (iv) respectively. This arbitrary assignment was also adopted in all the previous studies $[6,7,8]$.

Reports on fires furnished by the fire brigades in the United Kingdom contain information on the following two variables:

(1) area damaged by direct burning (fire area)

(2) total area damaged including smoke and water damage.

Only fire area has been considered for the damage, $A(t)$, in this study since it is only concerned with fire growth.

The data used in this investigation relate only to fires in buildings without sprinklers. Fires starting in access areas such as corridors, halls, lifts and stairs were excluded. A few fires for which information on discovery time was not available were also not included.

There were also a few fires with unusual or unacceptable combinations such as very low area damage but large control time. In some cases, the total damage (including smoke and water damage) was considerably high in comparison with very low fire damage. In these fires, most of the time (T) would have been associated with smoke and water rather than fire. These fires and those with unusual combinations mentioned earlier were also excluded as "outliers". Since the logarithm of damage was used for estimating the fire growth rate, a damage of one sq. metre was assigned to fires which were reported to have had no (zero) damage.

\section{RESULTS}

\subsection{Railway Properties}

The Home Office, United Kingdom which furnished the data was able to identify fires in all building structures connected with Railways by the use of Standard Industrial Classification (SIC) code 701 "Railways"; offices belonging to the railways were also included. It was not possible to identify uniquely railway stations or railway tunnels underground. If the fire was underground in either the railway tunnel or station it was coded to the use of the room as railway station and the floor of origin coded as a "basement". Similarly it was not possible to identify uniquely railway stations above ground as the use of the room was not necessarily coded to "railway station" if the fire started in a kitchen, cloakroom or access area. For the reasons mentioned above, the data provided by the Home Office related to railway properties generally and not particularly to railway stations, underground or above ground. 
It was also not possible to identify uniquely fires that started in trains since such cases were included in the "form of transport other than road vehicle". While there was no guarantee that such cases involved railway rolling stock, this source of ignition was the most likely in these fires occuring in railway properties. Most of the public places were identified through the code "places of assembly" for the item "use of room"; some public places were included in "other areas".

The estimated values of fire growth rates and doubling times are given in Table 1 . together with their maximum and minimum values and $A(0)$, the size of area initially ignited. Results are given separately for the two cases - the average rate $\beta$ for all fires as definied in equation (1) and the rate $\Theta$ for an individual fire as defined in equation (7). The formulae for standard deviations $\sigma_{\beta}$ and $\sigma_{\Theta}$ given in equations (4) and (12) were used for estimating the maximum growth rates through equation (5) for $\beta$ and equation (14) for $\Theta$. As one would have expected $\sigma_{\Theta}$ is considerably greater than $\sigma_{\beta}$; fluctuations around an individual value are considerably wider than fluctuations around an average. The average growth rate, moreover, includes fires with considerably low rates in which the areas damaged were small and burning periods high.

Considering all fires in railway properties for example, the maximum growth rate in an individual fire can be as high as 0.1066 (with a minimum doubling time of 6.5 minutes) compared with the maximum of 0.0417 for average growth rate (with a minimum doubling time of 16.6 minutes). Fires that started in public places had a higher growth rate than that for all fires. Fires that started in basements had a lower growth rate which was difficult to understand. The extent of fire spread, perhaps, does not depend on the floor of origin although it may be more difficult to fight a fire occuring in an underground area.

\subsection{Public Car Parks}

The Home Office Fire Statistics Section were able to identify all car parks with building structures excluding the following categories which were not considered in this study:
(a) outdoor car parks without structural boundaries
(b) car show rooms
(c) motor repair establishments
(d) private detached garages
(e) garages attached to dwellings
(f) car parks beneath flats and offices. 
Car parks for which data were obtained can generally be regarded as public car parks. According to the results given in Table 1. the rate of fire development in public car parks is practically the same as the rate for railway properties. Fires starting in the basements of car parks do not have a higher rate of fire growth.

\subsection{Road Tunnels and Subways}

The Home Office Fire Statistics Section were able to identify all fires starting in vehicles in road tunnels, underpasses and subways and those starting in tunnels. The latter category included all outdoor tunnels most of which were road tunnels; some rail and other tunnels might have been included but it was difficult to identify them due to the coding system.

The regression analysis (equation (2)) produced a very low growth rate of 0.0113 and hence, assuming $\mathrm{A}(0)=1$ equation (11) was adopted according to which

$\beta=\bar{y} / \bar{t}$

where, for $\mathrm{n}$ fires

$\bar{y}=\frac{1}{n} \Sigma \log A(t)$

is the average of logarithm of damage and $\bar{t}$ is the average of total duration of burning. This method produced an estimate of 0.0220 for the average growth rate $\beta$ which is also the expected value of growth rate $\Theta$ for an individual fire.

With $\bar{y}=\bar{Y}$, equation (12) has been used to estimate the standard deviation $\sigma_{\Theta}$ of $\Theta$.

Since,

$$
\sigma_{\mathrm{T}}^{2}=\frac{1}{\mathrm{n}} \Sigma\left(\mathrm{T}-\mu_{\mathrm{t}}\right)^{2}
$$

where $m_{t}=\vec{t}$, from equations (4), (12) and (13)

$$
\sigma_{\beta}^{2} / \sigma_{\Theta}^{2}=\left(\sigma_{\mathrm{T}}^{2}+\overline{\mathrm{t}}^{2}\right) / \mathrm{n} \sigma_{\mathrm{T}}^{2}=\frac{1}{\mathrm{n}}\left[1+\frac{\overline{\mathrm{T}^{2}}}{\sigma_{\mathrm{T}}^{2}}\right]
$$

Equation (16) has been used for deriving the standard deviation $\sigma_{\beta}$ of $\beta$ from $\sigma_{\ominus}$. The results are given in Table 1.

\subsection{Power Stations}

The Home Office Fire Statistics Section could not uniquely identify power stations but carried out a computer run to extract all fires starting in buildings linked to the "electricity" industry (SIC code 602) where the source of ignition was "power 
station equipment". The data furnished by them, therefore, did not include all power station fires. If they had done a run by the use of the SIC 602 and use of room BF "power house, switch gear, generator" that would have included all types of buildings not just relevant to power stations. Such a run was, hence, not carried out. The results are given in Table 1.

\section{SUMMARY AND CONCLUSIONS}

Using an exponential model and information on area damage and duration of burning in actual fires, fire growth rates have been estimated statistically for four types of occupancies. A clear distinction has been made between growth rates in individual fires and the average rate in all fires. As explained theoretically and through results, the maximun value (upper confidence limit) of growth rates in individual cases is considerably higher than the maximum value of the average rate. This is understandable since the standard deviation of an indivudual observation is higher than that of the average of several observations. The maximum rate among individual fires rather than the maximum of the average rate represents realistically the worst case scenario.

The results for Railway Properties indicate that the growth rate for fires which start in public places is higher than the overall rate for all fires. Fires starting in basements have a lower growth rate although it may be difficult to fight such fires. Perhaps, for this occupancy, the extent of fire spread does not depend on the floor of orgin. The rate of fire development in Public Car Parks is practically the same as the rate for Railway Properties, both with an average doubling time of 19 minutes and minimum doubling time in an individual fire of 7 minutes. Fires starting in the basement of car parks do not have a higher rate of growth. Fires in Road Tunnels and Subway have an average doubling time of 32 minutes and minimum doubling time in an individual fire of 12 minutes. Fire in Power Stations have growth rates approximately the same as those for Road Tunnels and Subways.

As pointed out in a previous paper [8], the fire growth rate based on equation (2) does not relate to any particular object. It is an average of the growth rates for several objects involved in a fire and takes into account the stochastic [10] (probalistic) nature of fire spread from object to object. This rate cannot, therefore, be compared directly with the growth rates based on heat output data provided by standard fire tests which only relate to individual objects. If experimental growth rates for different objects are combined using probabilities of fire spread as weights, the composite growth rate might correspond to the expected value of the growth rate estimated in this paper. The expected value would denote a medium fire and the maximum rate in an individual fire a fast fire. An ultra fast fire would, perhaps, correspond to the upper confidence limit of the growth rate in an individual fire, the probability of exceeding which is 0.01 . 


\section{REFERENCES}

1. Thomas, P.H. Fires in model rooms: CIB Research Programmes. Current Paper CP32/74. Fire Research Station, Borehamwood, Herts. 1974

2. Friedman, R. Quantification of threat from a rapidly growing fire in terms of relative material properties. Fire and Materials, 2, 1, 27-33, 1978.

3. Labes, W.G. The Elis Parkway and Gary dwelling burns. Fire Technology, 2, 4, 287-297, 1966.

4. Heskestad, G. Engineering relations for fire plumes. Society of Fire Protection Engineers, Technology Report 82-8, 1982.

5. Butcher, G. The nature of fire size, fire spread and fire growth. Fire Engineers Journal, 47, 144, 11-14, 1987.

6. Ramachandran, G. Economic value of automatic fire detectors. Building Research Establishment Information Paper 1P27/80, 1980.

7. Ramachandran, G. and Chandler, S.E. Economic value of early detection of fires in industrial and commercial premises. Fire Surveyor, 13(2), 8-14, 1984.

8. Ramachandran, G. Exponential model of fire growth. Fire Safety Science: Proceedings of the First International Symposium. (Eds) C.E. Grand and P.J. Pagni. Hemisphere Publishing Corporation, New York, 657-666, 1986.

9. Frishman, F. On the arithmetic means and variances of products and ratios of random variables. Statistical Distributions in Scientific Work, Volume 1. Models and Structures (Eds) G.P. Patil et al. D. Reidel Publishing Company, Dordrecht, Holland, 1975.

10. Ramachandran, G. Non-Deterministic modelling of fire spread. Journal of Fire Protection Engineering, 3 (2), 37-48, 1991. 
Table 1

Growth Rate and Doubling Time

\begin{tabular}{|c|c|c|c|c|c|c|c|c|c|}
\hline \multirow{2}{*}{$\begin{array}{l}\text { Occupancy } \\
\text { Type }\end{array}$} & \multirow{2}{*}{$\begin{array}{l}\text { Number of } \\
\text { Fires }\end{array}$} & \multirow{2}{*}{$\begin{array}{l}\text { Area initially } \\
\text { ignited } A(0) \\
\text { (sq. metre) }\end{array}$} & \multicolumn{3}{|c|}{ Average growth rate in all fires $(\beta)$} & \multirow{2}{*}{$\begin{array}{l}\text { Coefficient of } \\
\text { Variation of } \beta \\
\text { (Percentage) }\end{array}$} & \multicolumn{3}{|c|}{ Growth Rate in an individual fire $(\Theta)$} \\
\hline & & & \begin{tabular}{|l|} 
Expected \\
Value
\end{tabular} & $\begin{array}{l}\text { Standard } \\
\text { Deviation }\end{array}$ & \begin{tabular}{|l|} 
Maximum \\
Rate
\end{tabular} & & \begin{tabular}{|l|} 
Expected \\
value
\end{tabular} & $\begin{array}{l}\text { Standard } \\
\text { Deviation }\end{array}$ & \begin{tabular}{|l|} 
Maximum \\
Rate
\end{tabular} \\
\hline $\begin{array}{l}\text { Railway } \\
\text { Properties }\end{array}$ & & & & & & & & & \\
\hline $\begin{array}{l}\text { Fires in all } \\
\text { places }\end{array}$ & 776 & 1.0002 & $0.0376(18.4)$ & 0.0021 & $0.0417(16.6)$ & 5.6 & $0.0376(18.4)$ & 0.0352 & $0.1066(6.5)$ \\
\hline $\begin{array}{l}\text { Fires in public } \\
\text { places }\end{array}$ & 214 & 0.8 & $0.0454(15.3)$ & 0.0029 & $0.0511(13.6)$ & 6.4 & $0.0454(15.3)$ & 0.029 & $0.1022(6.8)$ \\
\hline $\begin{array}{l}\text { Fires in base- } \\
\text { ment }\end{array}$ & 66 & 0.82 & $0.0273(25.4)$ & 0.0039 & $0.0349(19.9)$ & 14.3 & $0.0273(25.4)$ & 0.0226 & $0.0716(9.7)$ \\
\hline $\begin{array}{l}\text { Public Car } \\
\text { Parks }\end{array}$ & & & & & & & & & \\
\hline \begin{tabular}{|l}
$\begin{array}{l}\text { Fires in all } \\
\text { places }\end{array}$ \\
\end{tabular} & 692 & 1.02 & $0.0362(19.1)$ & 0.0025 & $0.0411(16.9)$ & 6.9 & $0.0362(19.1)$ & 0.0318 & $0.0985(7.0)$ \\
\hline \begin{tabular}{|l|} 
Fires in base- \\
ment
\end{tabular} & 165 & 1.26 & $0.0366(18.9)$ & 0.0058 & $0.0480(14.4)$ & 15.8 & $0.0366(18.9)$ & 0.0327 & $0.1007(6.9)$ \\
\hline \begin{tabular}{l|} 
Road Tunnels \\
and Subways
\end{tabular} & 107 & 1.00 & $0.0220(31.5)$ & 0.0024 & $0.0267(26.0)$ & 10.9 & 0.0220 & 0.0176 & $0.0565(12.3)$ \\
\hline \begin{tabular}{|l|}
$\begin{array}{l}\text { Power } \\
\text { Stations }\end{array}$ \\
\end{tabular} & 115 & 0.93 & $0.0208(33.3)$ & 0.0029 & $0.0265(26.2)$ & 13.9 & $0.0208(33.3)$ & 0.021 & $0.0620(11.2)$ \\
\hline
\end{tabular}

The figures within brackets are corresponding doubling times in minutes. 
